\title{
Numerical Simulation of Middle Thick Plate in the U-Shaped Bending Spring Back and the Change of Thickness
}

\author{
Jianhua Ren ${ }^{*}, 1$ and Xiaogang Guo ${ }^{2}$ \\ ${ }^{1}$ Hebei University of Engineering, Hebei, Handan, China \\ ${ }^{2}$ Beijing Vertical and Horizontal Electrical and Mechanical Technology Development Company, Beijing, China
}

\begin{abstract}
In this paper, the typical U-shaped pieces were taken as the object of study and the finite element numerical simulation software Dynaform is applied to simulate the effect of sheet metal bending. The U-shaped bending spring back and its thickness change are analyzed. The influence law of main parameters of die structure to sheet thickness change and the spring back amount are obtained by combining with the orthogonal analysis method. Finally a set of the optimal parameter combination is found, the spring back of U-shaped piece and the change of the thickness are controlled in a reasonable range.
\end{abstract}

Keywords: Middle thick plate, orthogonal analysis, U-bend.

\section{INTRODUCTION}

Sheet metal bending is a complicated process, after bending, not only the spring back affect occurs but also its thickness will reduce. Spring back affects the accuracy of part, and reduction of thickness affects the strength of part $[1,2]$. There are many parameters that affect the quality of curved pieces and in the structure of mold, die clearance, coefficient of friction, punch round radius, die round radius and other major factors affect the quality of curved pieces, and also the values of parameters change within a range. So it is very difficult to accurately count values of spring back and reduction of thickness in theory.

The finite element numerical simulation software Dynaform can simulate the process of sheet metal bending, and predict the result of sheet metal bending accurately. Orthogonal analysis method is a scientific and powerful multi-parameter and multiple level experimental design method, which is based on the mathematical statistics, with the most appropriate test times it has the most accurate results. U-shaped bending is a kind of typical sheet metal bending type.

\section{THE SPRING BACK OF SHEET METAL BENDING AND THINNING OF THICKNESS}

When the sheet metal is bended, its outer fiber is under tension, and here tensile stress and tensile strain in the tangential are produced. The inner fiber is compressed, and here compressive stress and compressive strain in the tangential are produced. Sheet metal bending process is a transition from elastic deformation to plastic deformation, the total deformation is the stack of elastic deformation and plastic deformation, and elastic deformation exists in the whole deformation process $[3,4]$. When the sheet metal is deformed under the application of force and returns to its original shape after the force is removed is known as elastic deformation but when the when the sheet metal does not return to its original shape then it is known as plastic deformation. There is a slight elastic recovery due to the existence of residual force which is known as spring back. When Sheet metal bends, the outer part of the sheet metal tends to thin with the bending deformation because of the existence of tensile strain; on the contrary, the inner sheet metal will tend to thicken with the bending deformation because of the existence of compressive strain. And in the process of bending, neutral layers would move to direction of the flexural center, so this leads to that that the thinning amount of sheet metal outer layer is greater than the thickening amount of sheet metal inner layer. Therefore, the phenomenon of sheet metal bending for thinning will be more and more obvious with the increase of bending deformation degree [5].

Die structure parameters affecting the quality of bending deformation.

As shown in Fig. (1), the stress distribution on a Ushaped bending moment of an axisymmetric piece is analyzed. According to the force balance condition the axial force formula is as follows:

$2 \mu N \sin \theta+2 N \cos \theta=F$

In the formula, $\mathrm{N}--$ the support force of die to sheet metal;

$\mu$-coefficient of friction;

$\theta$-the angle of Sheet metal bending;

$F$ - punch force of sheet metal. 


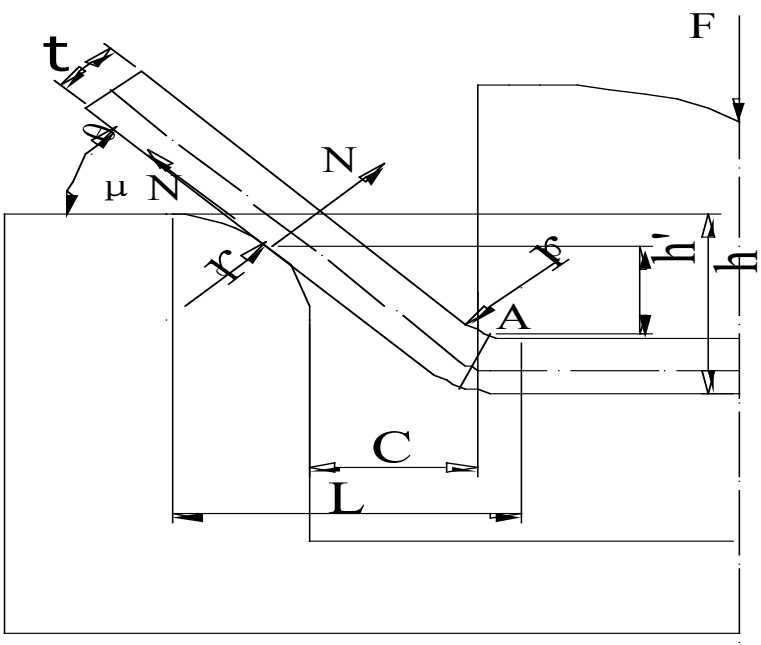

Fig. (1). U-shaped bending.

The deformation is:

$P=k_{n}\left(\frac{E_{1}}{k}\right)^{2} \frac{1}{f}+k_{c}\left(\frac{E_{1}}{k}\right)^{2}+k_{e}\left(\frac{E_{1}}{k}\right)^{1.5}$

Suppose punch contacts with the sheet metal on point A, the external forces at point A neutral layer interface of bending moment is:

$B=B_{r} r+B_{z} z$

According to the formula (2) and formula (3):

$M_{A}=\frac{\left(\mu t+h^{\prime} / \sin \theta+t / \tan \theta\right) F}{2(u \sin \theta+\cos \theta)}$

According to the geometric structure of Fig. (1):

$h^{\prime}=h-t-\left(r_{p}+r_{d}\right)(1-\cos \theta)$

In the formula,

$h$-punch stroke;

$t$-the thickness of the sheet metal;

$P_{E}=\frac{1}{24 \rho} \omega^{2} d^{2} B^{2} \quad W / m^{3} \quad-$ punch round radius;

$P_{E r i}=\frac{1}{24 \rho}\left(B_{r i} b \omega\right)^{2} 2 \pi R_{i} S_{i}-$ die round radius.

At the same time is:

$P_{E z i}=\frac{1}{24 \rho}\left(B_{z i} d \omega\right)^{2} 2 \pi R_{i} S_{i}$

$P_{E}=\sum_{i=1}^{N}\left(P_{E r i}+P_{E z i}\right)$

In the formula, $\mathrm{C}$ - die clearance.

So by the formula (4), (5), (6) and(7), (8) is obtained:

$$
F=\frac{2\left(\mu \sin ^{2} \theta+\sin \theta \cos \theta\right)}{\mu t \sin \theta+h-t-\left(r_{p}+r_{d}\right)(1-\cos \theta)+\frac{(C \sin \theta-1) t}{h-t-\left(r_{p}+r_{d}\right)(1-\cos \theta)}} M_{A}
$$

If the internal bending moment of sheet metal is $M_{Q}$, so according to the condition which internal and external bending moment are equal in the bending process:

$M_{A}=M_{Q}$

If hardening of sheet metal bending is not considered, so $M_{Q}$ is:

$M_{Q}=\frac{1}{4} b t^{2} \sigma_{s}$

In the formula, $\mathrm{b}$ - -sheet metal width;

$\sigma_{s}-$ sheet metal yield strength.

So the formula (8) is:

$F=\frac{1}{2} \frac{\left(\mu \sin ^{2} \theta+\sin \theta \cos \theta\right) b t^{2} \sigma_{s}}{\mu t \sin \theta+h-t-\left(r_{p}+r_{d}\right)(1-\cos \theta)+\frac{(C \sin \theta-1) t}{h-t-\left(r_{p}+r_{d}\right)(1-\cos \theta)}}$

So the parameters die clearance, friction coefficient, punch round radius, die round radius affects the deformation force of U-shaped bending, then these parameters also affect the internal stress and strain of U-shaped bending, and finally affect the forming quality of U-shaped parts [6]

\section{U-SHAPED PIECE PART DRAWING AND MATERIAL PARAMETERS}

Fig. (2) shows a typical and simple U-shaped piece part drawing, the thickness of plate is $5 \mathrm{~mm}$. The opening size of the part is mainly controlled, whose deviation is $0.5 \mathrm{~mm}$ and material parameters are shown in Table $\mathbf{1}$.
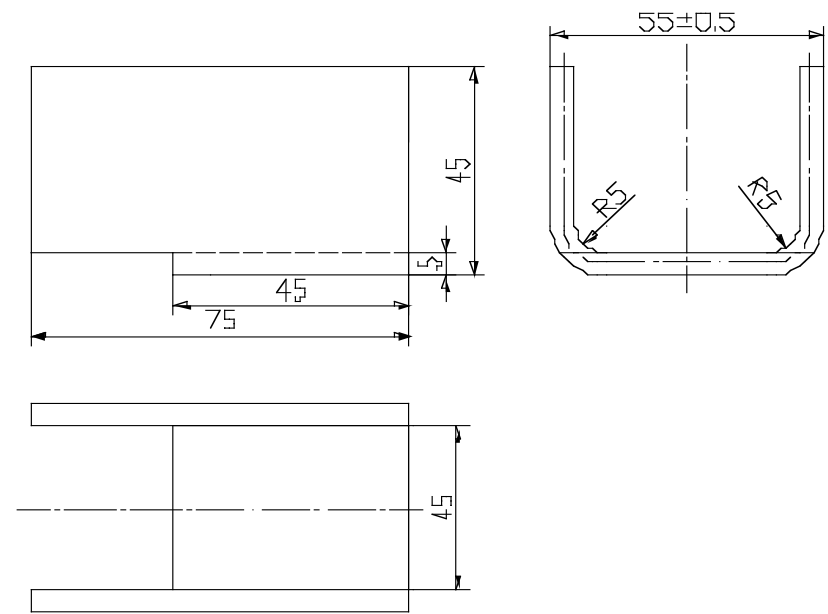

Fig. (2) U-shaped piece part drawing.

Table 1. The main material parameters of Q235.

\begin{tabular}{|c|c|c|c|c|c|c|}
\hline Material & $\sigma_{\boldsymbol{S}} / \boldsymbol{M P A}$ & $\boldsymbol{\sigma}_{\boldsymbol{b}} / \boldsymbol{M P A}$ & $\boldsymbol{E} / \boldsymbol{G P a}$ & $\boldsymbol{\mu}$ & $\boldsymbol{K} / \boldsymbol{M P a}$ & $\boldsymbol{n}$ \\
\hline \hline $\mathrm{Q} 235$ & 240 & 380 & 207 & 0.28 & 630 & 0.236 \\
\hline
\end{tabular}




\section{MOLD MODEL OF U-SHAPED BENDING AND THE SIMULATION OF PRINCIPAL STRESS DISTRIBUTION INSIDE THE PLATE}

\subsection{Mold Model of U-Shaped Bending}

Among many theoretical researches, the form of pressure side bending is used to reduce the spring back of U-shaped parts. However, the form of pressure side bending is not used to reduce the complexity of the stamping process in the actual production.

In this paper, non-pressure side of the mold structure is used for the study. Fig. (3) shows CAD model of the bending die of U-shaped part.

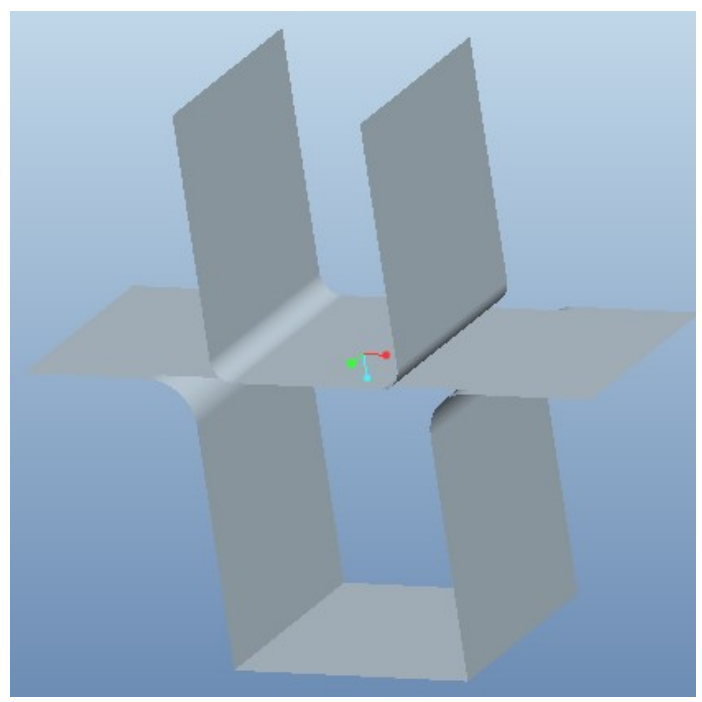

Fig. (3). CAD model of the bending die of U-shaped part.

4.2. The Simulation of Principal Stress Distribution Inside the Plate Before and After Spring Back

According to the mold model of U-shaped bending, applying the finite element numerical simulation software Dynaform simulates the situation of sheet metal bending. After stamping, Figs. (4, 5) shows internal principal stress distribution contour of sheet metal before and after spring back. Through the contrast of the two figures, it can be seen that the internal principal stress of part has reduced visibly after spring back in the bending deformation zone. Investigating its reason, this is caused by elastic deformation recovery and residual stress of plastic deformation recovery after spring back. This also leads to a change in the size of stamping part, and impacts manufacturing precision of part.

\section{THE ORTHOGONAL DESIGN OF EXPERIMENT AND FINITE ELEMENT NUMERICAL SIMULATION OF U-SHAPED BENDING}

5.1. The Main Parameters of the Mold Structure and its Level

In the structure of the mold, the main parameters are die clearance, coefficient of friction, punch round radius and die round radius, which affect the quality of bending parts $[7,8]$. And these parameter's sizes will change within a certain range. So, the sizes of these parameters have a direct impact on the quality of the curved parts, each parameter's sizes as follows:

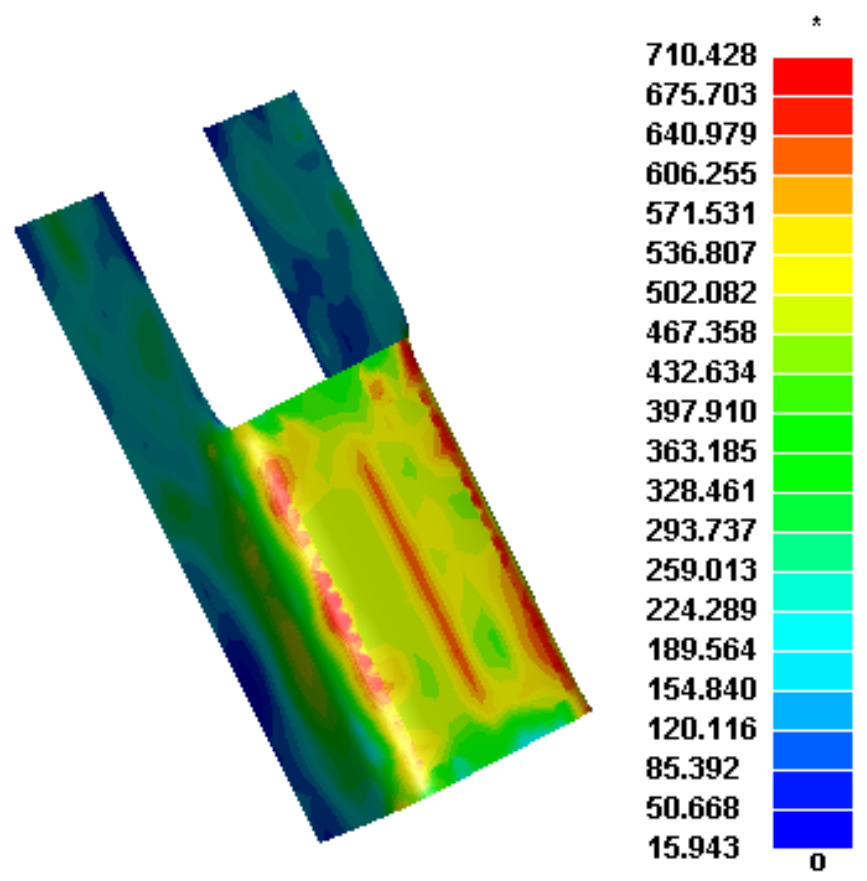

Fig. (4). Stress contour of before spring back.
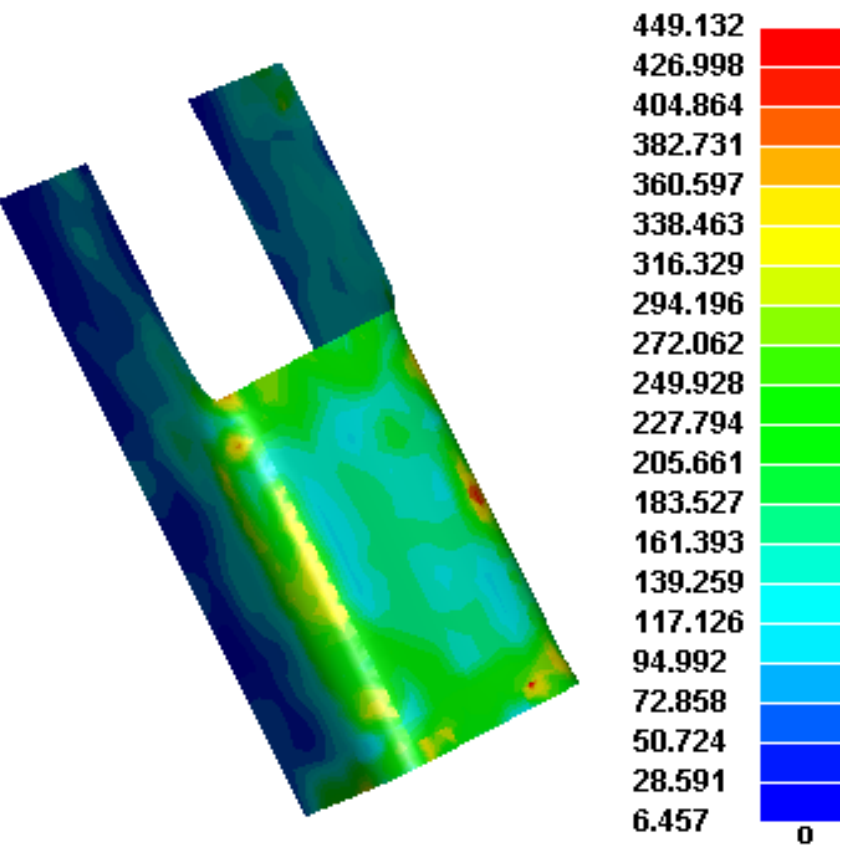

Fig. (5). Stress contour of after spring back.

\subsubsection{Die Clearance C}

In the die structure, the size of die clearance effects the spring back of part, surface quality and the size of the bending force, the greater the size of die clearance, the greater the amount of the spring back of the part and the smaller the size of die clearance, the greater the amount of the thickness reduction ratio. According to the empirical formula, the size of die clearance is always $1.05 \sim 1.2 \mathrm{t}$. So, its level in the simulation experiment is taken as $1.05 \mathrm{t}, 1.1 \mathrm{t}$, $1.15 \mathrm{t}$ and $1.2 \mathrm{t}$. 


\subsubsection{Coefficient of Friction $\mu$}

In the process of stamping, there is a relative slip between sheet metal and die. The size of coefficient of friction affects the quality of forming parts, So according to the reference [7], its level taken as $0.1,0.125,0.14$, and 0.16 .

\subsubsection{Punch Round Radius $r$}

The size of punch round radius is based on the rounded size inside the part. The size of punch round radius determines the relative bending radius of the sheet. When the size of thickness is constant, the smaller size of punch round radius, the greater degree of sheet metal bending. According to Fig. (1), the rounded size inside the part is $5 \mathrm{~mm}$, if the size of punch round radius is too small; it may creak after bending. So, its level is taken as $5 \mathrm{~mm}, 7.5 \mathrm{~mm}, 10 \mathrm{~mm}$ and $12.5 \mathrm{~mm}$ 。

\subsubsection{Die Round Radius $R$}

The size of the die round radius is according to the thickness of the sheet metal. When the thickness $t>4 \mathrm{~mm}$, the size of the die round radius is always $2 \mathrm{t}$. In the simulation experiment, its size is about $2 \mathrm{t}$, so its level is taken as $7.5 \mathrm{~mm}, 10 \mathrm{~mm}, 12.5 \mathrm{~mm}$, and $15 \mathrm{~mm}$.

\subsection{Orthogonal Experimental Design and Finite Element Numerical Simulation}

\subsubsection{The Determination of Experimental Index}

There are two experimental indexes in the orthogonal experiment, one is spring back of opening size of U-shaped part's neutral layer--- $\triangle \mathrm{L}$, as shown in the Fig. (6). Another is thinning rate of plate's thickness--- $\delta$, the size is the percentage of part's thinning after been bended and plate's thickness.

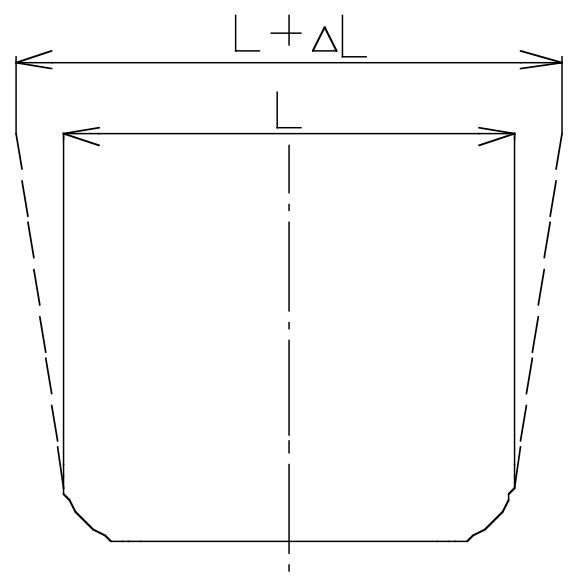

Fig. (6). Spring back of opening size of part.

\subsubsection{The Selection of Orthogonal Table and the Result of Finite Element Numerical Simulation}

There are four parameters of die structure in the simulation experiments, and every parameter has four levels, so the selection of orthogonal table is $L_{16}\left(4^{5}\right)[9,10]$. All the arrangements of the orthogonal experiment are listed in the Table 2.

There are 16 simulation experiments and the corresponding parameters in the Table 2. Now apply the finite element numerical simulation software Dynaform to simulate the effect of sheet metal bending based on the first simulation experiment. After the sheet metal forming, the part's thickness distribution of the cloud can be obtained and the opening size of neutral layer can be measured after spring back.

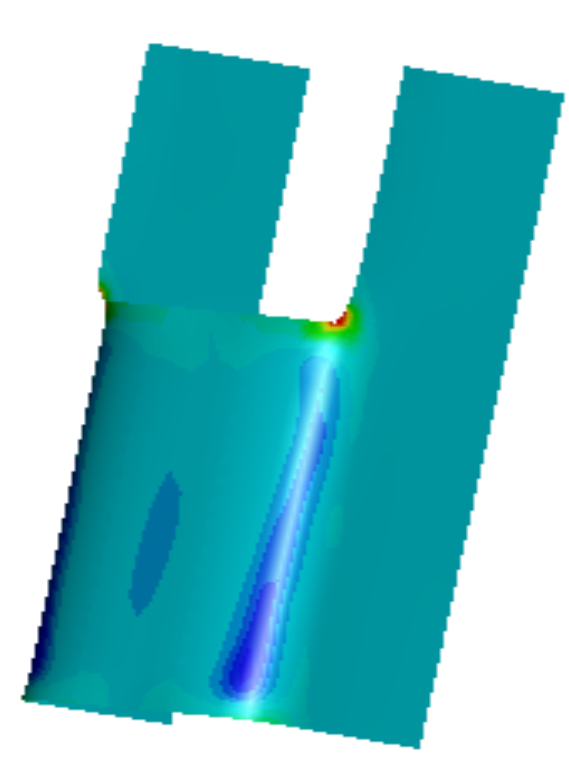

4.713

4.732

4.750

4.769

4.788

4.806

4.825

4.843

4.862

4.880

4.899

4.917

4.936

4.954

4.973

4.991

5.010

5.028

5.047

5.065

5.084

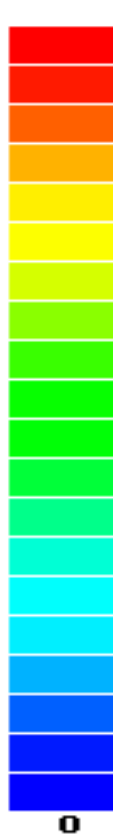

Fig. (7). Part's thickness distribution of the cloud.

Fig. (7) shows the part's thickness distribution of the cloud, the biggest thinning rate of plate's thickness is 5.73\%.

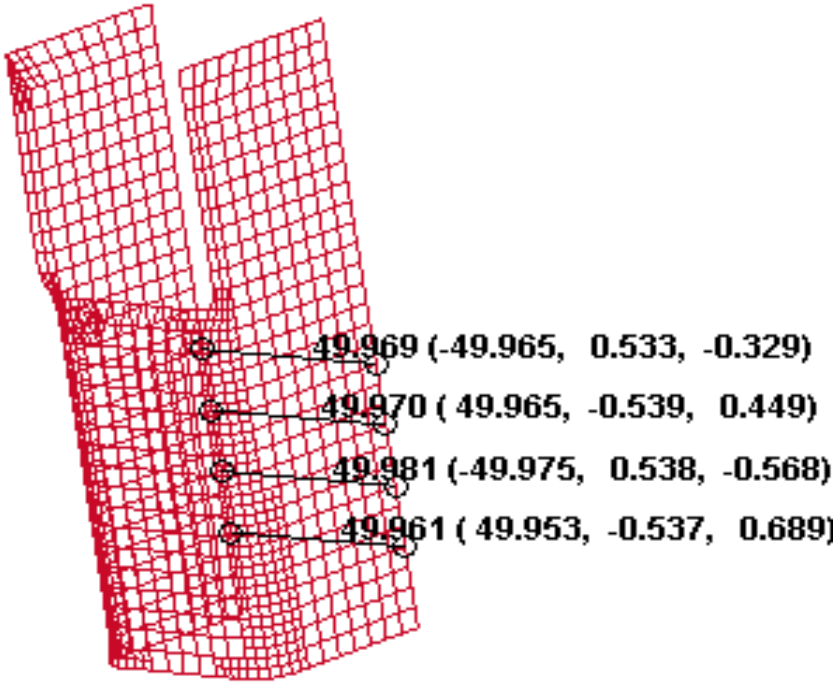

Fig. (8). Part's opening size of sections.

Fig. (8) shows opening sizes of the four sections, neutral layer represents the whole part in software Dynaform, so the average of opening size is -0.031 . Then apply the finite element numerical simulation software Dynaform to simulate the situation of sheet metal bending to the remaining 15 simulation experiments, thinning rates of plate's thickness and spring back of opening sizes are listed in the Table 2. 
Table 2. The arrangement of the orthogonal experiment and the simulation results.

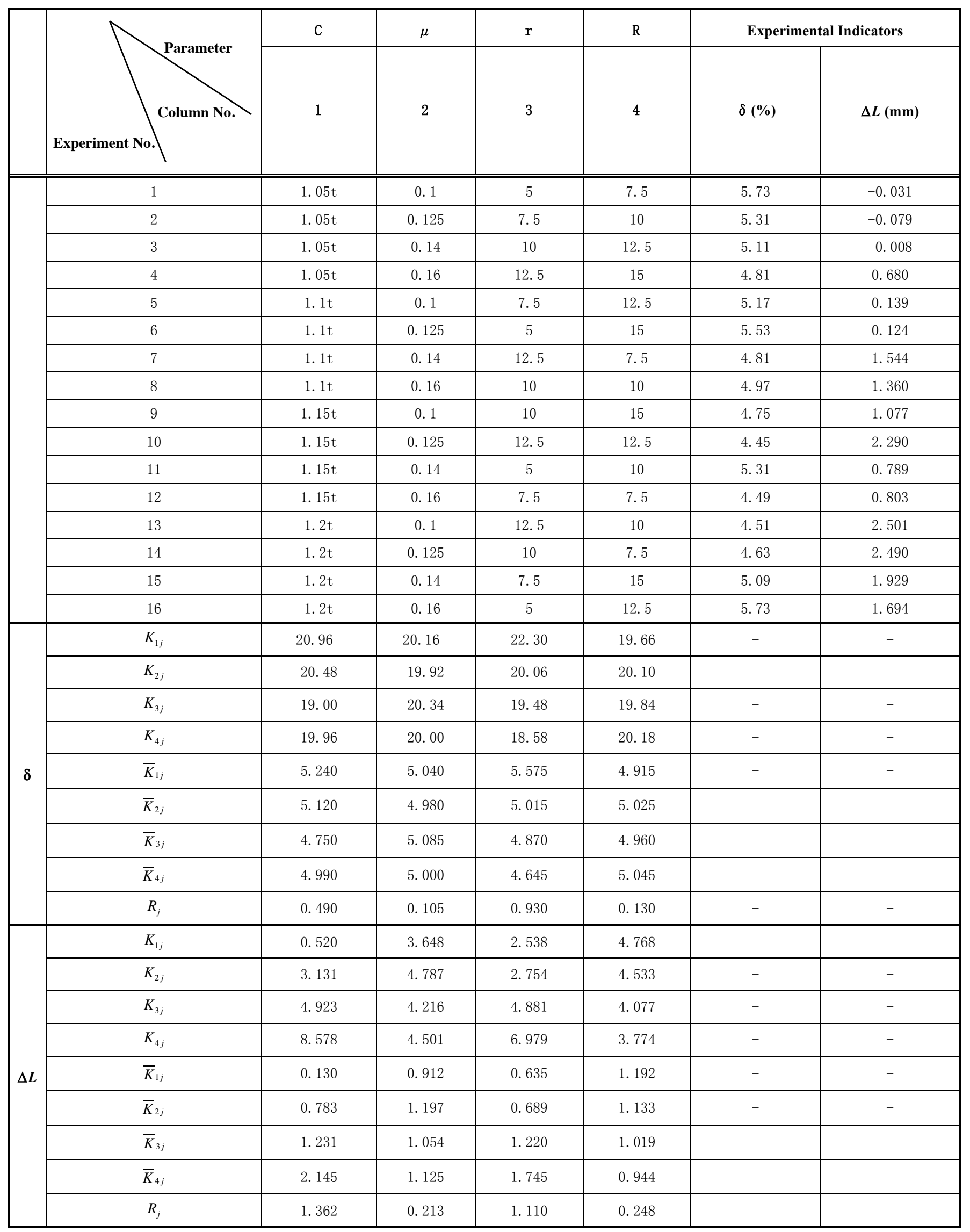




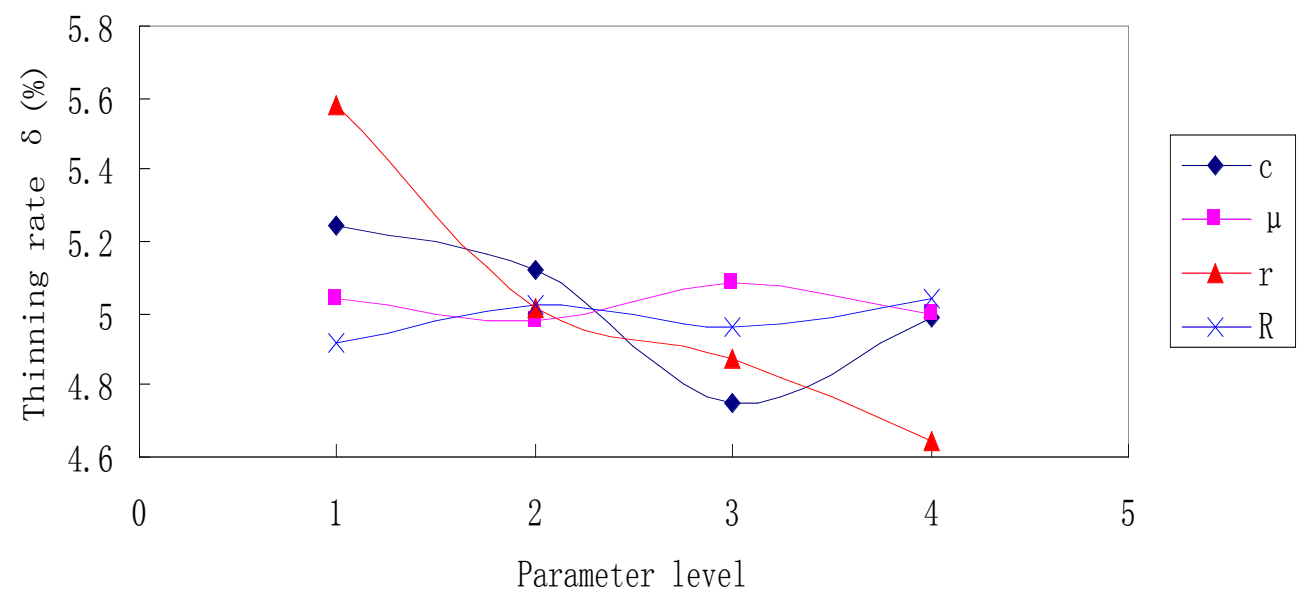

Fig. (9). The impact trend graph of various parameters to thinning rate.

\section{VISUAL ANALYSIS OF ORTHOGONAL EXPERIMENTAL RESULTS}

\subsection{The Effects of Parameters on the Thickness Changes}

If $R_{j}$ is greater, the parameter has a greater degree of influence to the experimental index. From Table $\mathbf{2}$ it is evident, that the ranges of the parameters of thinning rate are as follow: $R_{3}>R_{1}>R_{4}>R_{2}$. This shows that the punch round radius has the greatest influence to thinning rate, while the coefficient of friction has the minimum influence. If the level of each parameter as the abscissa and the average of thinning rate as the ordinate, the impact trend graph can be drew in Fig. (9), which expresses the trend of various parameters to thinning rate.

\subsection{The Influence of Parameters on Spring Back}

The ranges of the parameters of part's opening size are as follow: $R_{1}>R_{3}>R_{4}>R_{2}$. This shows that the die clearance has the greatest influence to thinning rate, while the coefficient of friction has the minimum influence.

If the level of each parameter as the abscissa and the spring back of opening size of parts as the ordinate, the impact trend graph can be drawn as in Fig. (10), which expresses the trend of various parameters to spring back of opening size of parts.

\section{ANALYSIS OF OPTIMAL PARAMETER COMBINATION}

Based on the above analysis, a set of relatively optimal levels of each parameter eventual combination are: $1.05 \mathrm{t}$, $0.1,5$ and 7.5. This set of parameters is the combination of the first group of parameters in Table 2 , the thinning rate is $5.73 \%$ and the spring back of opening size is $-0.031 \mathrm{~mm}$. So the combination of parameters is feasible, and can ensure good accuracy of parts. According to the result of the mould structure parameter optimization, the initial mold structure is improved and the final structure size is obtained, which is shown in Fig. (11). Through the new mould, the qualified parts are produced

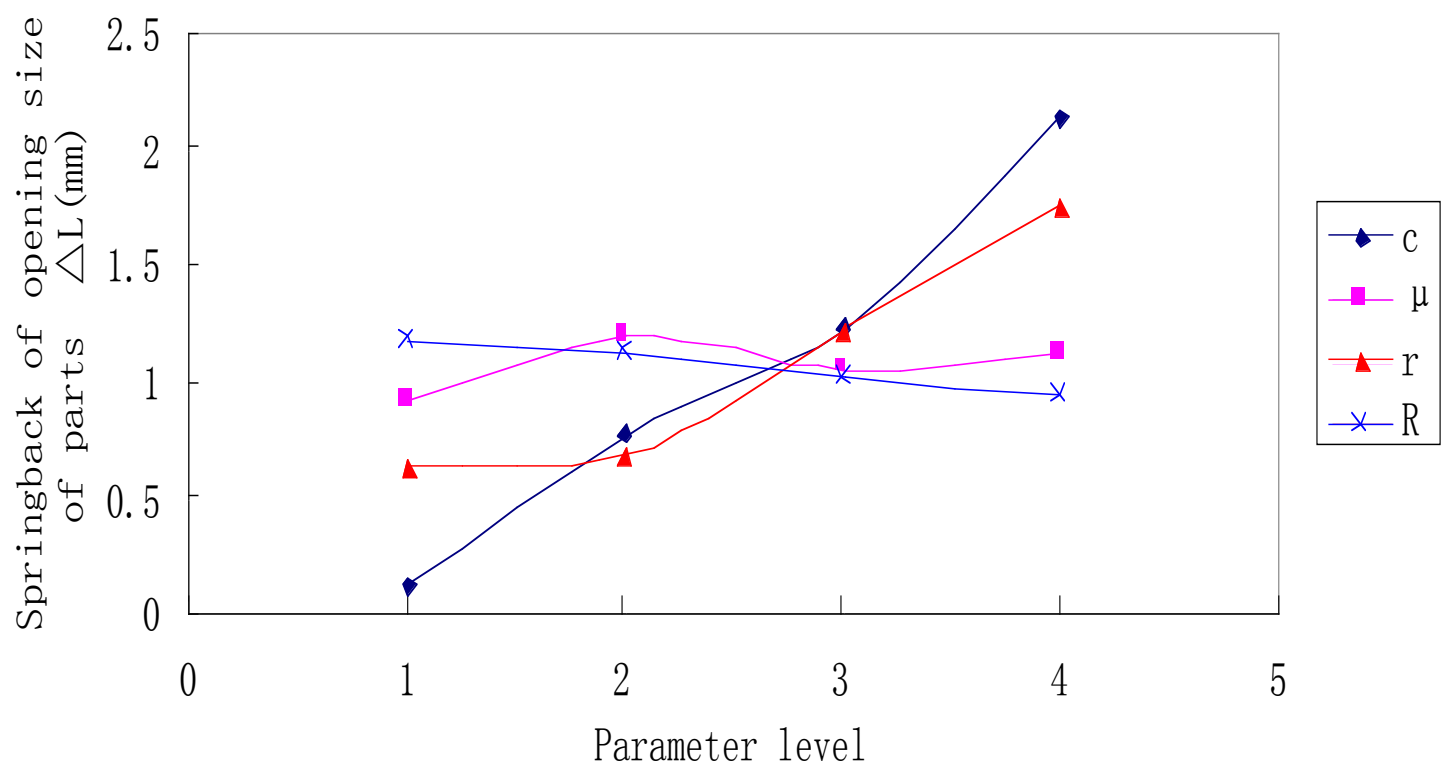

Fig. (10). The impact trend graph of various parameters to spring back of opening size of parts. 


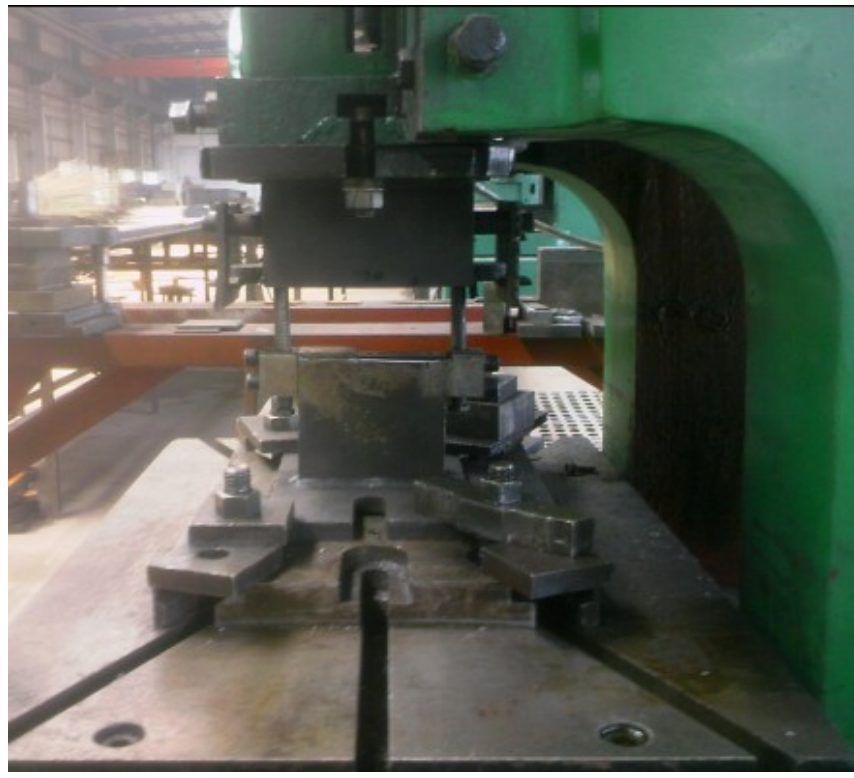

Fig. (11). The bending and discharging mould.

\section{CONCLUSION}

Through the study of this paper the following conclusions are obtained:

(1) In the main parameters of mold, the punch round radius has the greatest influence to thinning rate, while the die clearance has the greatest influence to plate bending spring back.

(2) Through the orthogonal experimental method, we can effectively reduce the number of finite element numerical simulation, and be able to make the optimization for combination of mold structure's parameters.

(3) In the middle thick plate bending, thinning rate should not be ignored to improve the quality of plate bending.
(4) The mould optimization result is verified through trial production mould and stamping U-shaped parts.

\section{CONFLICT OF INTEREST}

The authors confirm that this article content has no conflict of interest.

\section{ACKNOWLEDGEMENTS}

Declared none.

\section{REFERENCES}

[1] J. P. Pempsey, Z. G. Zhao, and H. Li, "Axisymmetric indentation of an elastic layer supported by a Winkler foundation," International Journal of Solids and Structures, vol. 27, no. 1, pp. 73-87, Jan 1991.

[2] H. Gunaglin, L. Jinfu, and M. Hailin, "Wide plate thickness variation law in the process of forming," Journal of Plasticity Engineering, vol. 12, pp. 48-51, Aug 2006.

[3] W. Yihua, L. Wenbo, and H. Chengbin, "The new theoretical solution of perfectly plastic sheet bending thinning," Mold Industry, vol. 5, pp. 24-48, Apr 2011.

[4] C. Wenlin, C. Xuewen, and C. Xiaoqin, Sheet metal forming technology and die design. Beijing: Machinery Industry Press, 2011.

[5] L. Puping, "Finite element analysis software Dynaform-PC in the application of stamping technology," Journal of Suzhou Vocational University, vol. 2, pp. 77-79, Mar 2005.

[6] J. Minghua, Y. Juntao, and X. Ting, "Commentary of sheet metal forming and spring back simulation," Forging \& Stamping Technology, vol. 12, pp. 1-5, Oct 2007.

[7] H. Xueyan, G. Jinjin, and X. Yadong, "Orthogonal test method in the application of $U$ shaped pieces of spring back numerical simulation," Machine Tool and Hydraulics, vol. 4, pp. 128-134, Jan 2009.

[8] H. Wei, and H. Yingwei, "Numerical simulation of middle thick plate bending process," Forging \& Stamping Technology, vol. 4 pp. 165-168, Dec 2010.

[9] Z. Jun, S. Chunjian, and G. Yingping, "Numerical analysis of factors influencing spring back of U-bending," Forging \& Stamping Technology, vol. 12, pp. 136-140, Sep 2007.

[10] W. Peng, and D. Xianghuai, "The numerical simulation of Uchannel spring back and optimization of forming parameters," Journal of Shanghai Jiaotong University, vol. 10, pp. 1592-1598, June 2007. 